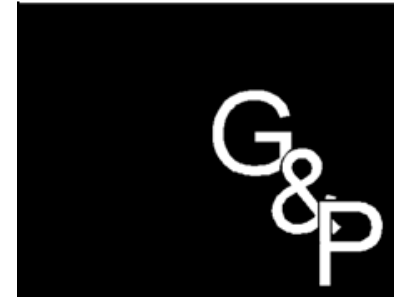

GESTÃO

$\&$

PRODUÇÃO

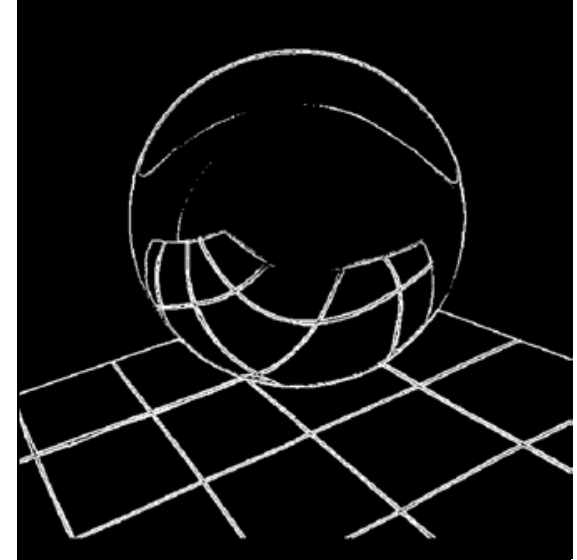

v.7, n.1, p. 43-55, abr. 2000

\section{ABORDAGEM SISTÊMICA DO GERENCIAMENTO PELAS DIRETRIZES: CONCEITUAÇÃO E APLICAÇÃO}

Ralph Santos da Silva

Fundação Centro Tecnológico para Informática - Campinas - SP E-mail: ralph@ia.cti.br

Pedro Luiz de Oliveira Costa Neto Fundação Vanzolini - São Paulo - SP E-mail: pluiz@vanzolini-ead.org.br

\title{
Resumo
}

Este artigo apresenta um modelo teórico do Gerenciamento pelas Diretrizes (GD), organizando suas principais características sob uma ótica conceitual, explorando os seus aspectos orgânicos. Inicialmente, é estabelecido o seu processo característico para, em seguida, serem definidos quatro elementos que o complementam: (1) sistema de priorização; (2) dispositivos estruturais; (3) dispositivos conciliadores; e (4) sistema de informação. A partir desta referência e por meio da pesquisa-ação é articulada sua implementação numa empresa de serviços que atua como distribuidor de cerveja, atendendo uma grande região geográfica. Desta intervenção, surgem novas características que contribuem para o aprimoramento da proposta.

Palavras-chave: gestão pela qualidade total, gerenciamento pelas diretrizes.

\section{Introdução}

Aanos vem sendo modificada constantemente. Este processo evolutivo promove sua adaptação às necessidades correntes. Tal fato vem se dando por meio da formação de um complexo aparato constituído por várias metodologias, métodos e ferramentas, criadas para a resolução de problemas vivenciados pelos vários setores que compõem uma organização. Muitas vezes, a correta utilização de qualquer um deles requer a formação de equipes de trabalho, que podem ser funcionais ou interfuncionais, podendo cada 
integrante pertencer indistintamente a qualquer nível hierárquico existente na empresa.

Dentre algumas soluções existentes, destacase o Gerenciamento pelas Diretrizes (GD), que é o principal mecanismo de sustentação da Gestão pela Qualidade Total (GQT) conforme AKAO (1991). No contexto organizacional tem como função principal harmonizar os interesses de longo prazo com a capacidade de inoção da empresa que contempla a voz do cliente como elemento catalizador para o processo de melhoria no curto e médios prazos.

O GD pode ser entendido como um mecanismo, que viabiliza a identificação da diferença entre o que a empresa pode fazer e o que ela deve fazer. Esta disparidade pode ser neutralizada com a formulação de diretrizes a serem implementadas por meio de processo que contém dispositivos de monitoramento das ações sobre os processos e sobre os resultados.

Para atender tal objetivo, o GD tem em sua base de sustentação três propósitos:

- alinhar a empresa em torno de objetivoschave a serem alcançados, estabelecendo um senso de urgência, inclusive fazendo com que cada um consiga avaliar a contribuição estratégica que pode ser dada para atingir o que tenha sido estabelecido;

- alinhar todos os trabalhos e tarefas em direção aos objetivos-chave a serem alcançados e, em seguida, promover as inovações necessárias, focalizando e coordenando os esforços e recursos;

- atuar rápida e eficientemente, em consonância com a rápida mudança do ambiente externo em que a empresa se encontra.

Inicialmente, é importante destacar que o GD não tem como objetivo concorrer com quaisquer que sejam os mecanismos que tratam a estratégia da empresa; muito pelo contrário, ele pode ser caracterizado para aquelas situações em que a empresa não desfruta de tradição no estabelecimento de plano estratégico, por conciliar os interesses de longo prazo, que passam a orientar as ações de curto prazo para os níveis operacionais.
Para as empresas que desfrutam de uma estruturação sistemática do plano estratégico, a integração do GD pode ocorrer naturalmente, conforme mostra a Figura 1. Na sua parte superior temos os elementos comumente encontrados na formulação do plano estratégico, e na sua parte inferior temos os elementos que caracterizam o GD. Este pode e deve ser utilizado, principalmente quando consideradas a formulação e a operacionalização do plano anual.

Como mostrado na Figura 1, a visão no longo e médio prazo deve ser ajustada em consideração às mudanças do ambiente externo. Por meio do plano de médio prazo é estabelecido o plano anual, que é submetido a um desdobramento até atingir os níveis operacionais. Este, resumidamente, caracteriza-se por apresentar os seguintes atributos:

desdobramento anual = descrição dos caminhos a serem seguidos no ano + meios de acompanhamento + métricas + objetivos + datas limites

Sua relação com outros mecanismos, tais como o gerenciamento do cotidiano, discutido em CAMPOS (1992), MORAN et al (1991) e HARRIGNTON (1988), ou mesmo a avaliação sistemática dos processos de negócio, como discutido em HARRIGNTON (1993) ou DAVENPORT (1993), é definida colocando o GD como o provedor da escolha de um ou outro, dependendo da natureza do problema a ser resolvido. Isto é, se ele necessita de alguma revisão localizada de atividades repetitivas ou se ele envolve questões interfuncionais. Em MELUM \& COLLETT (1995) é apresentada uma precedência entre estes dois mecanismos e o Gerenciamento pelas Diretrizes. Esta precedência vem sendo encontrada em várias empresas americanas que estão implementando a GQT como mostrada na Figura 2.

Os benefícios apontados quando se submete uma empresa ao processo característico que estabelece as diretrizes são: 


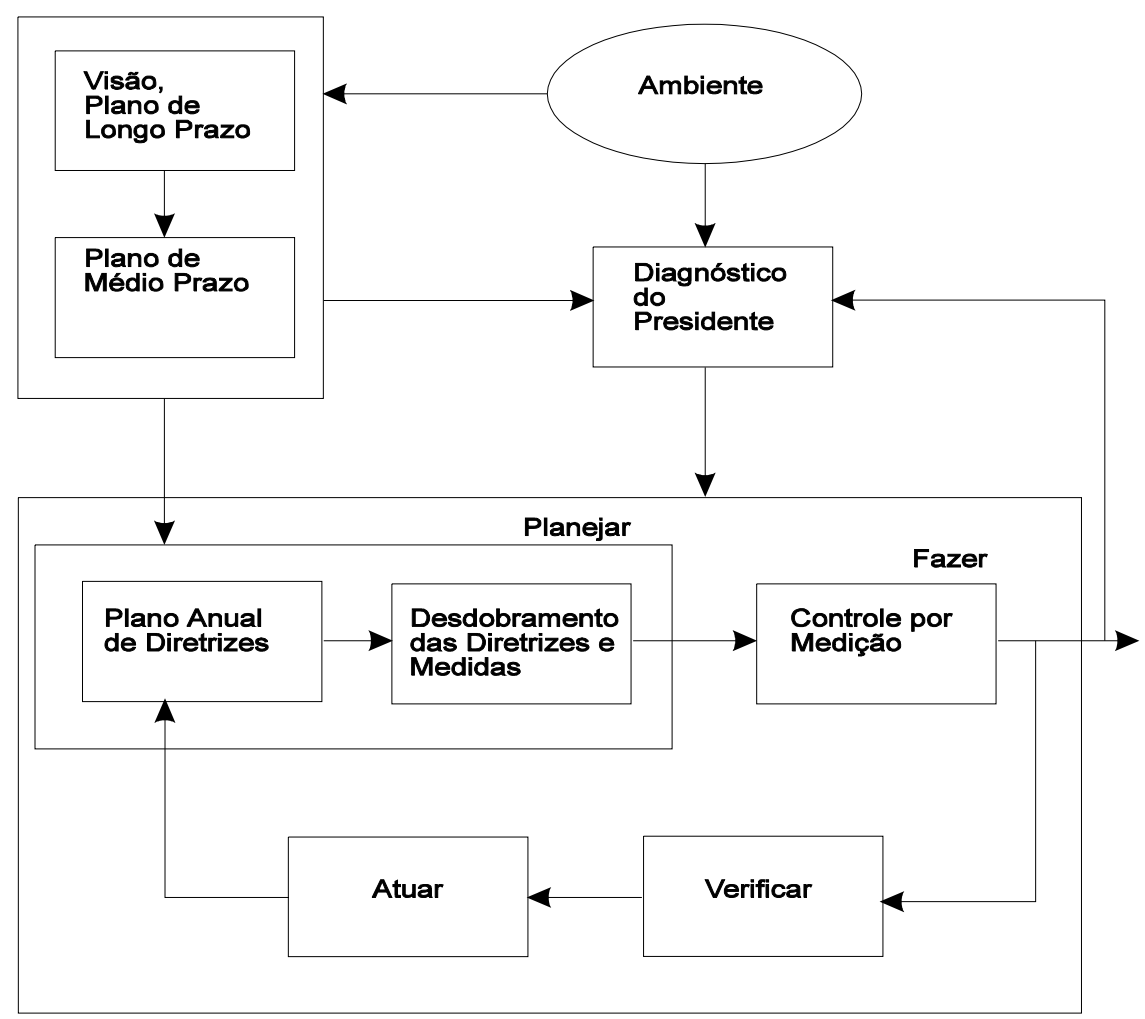

Figura 1 - Processo característico do Gerenciamento pelas Diretrizes (SHIBA et al, 1993).

- Focalização: considerando a voz do cliente, promove-se um exercício que leva a empresa a focalizar-se nos principais pontos, poucos mas vitais, que tragam resultados significativos pelo tratamento adequado do processo.

- Alinhamento: sendo um propósito para atingir-se os objetivos inicialmente estabelecidos, o GD propõe dispositivos que alinhem os esforços daqueles envolvidos nos processos e/ou atividades quotidianas escolhidos.

- Conhecimento coletivo: por ser um processo que promove uma ampla discussão em todos os níveis dentro da empresa, este fato acaba por gerar uma base de conhecimento bilateral, tornando público o conhecimento de cada um no processo em que participa.

- Enobrecimento dos empregados: como a participação de todos acaba por acontecer, os envolvidos são levados a participar não só como executores de um plano, mas atuam também como verdadeiros artesãos das possíveis implementações que dar-se-ão ao longo da trajetória, que levará a empresa a caracterizar uma inovação no processo explorado.

Fortalecimento dos times de trabalho: a mobilização feita, que tem como principal objetivo resgatar a participação dos empregados em questões cruciais da empresa, propicia uma convergência sinérgica dos times, de forma natural e coesa.

Por fim, são apontados os fatores que podem contribuir decisivamente para o sucesso da implantação do Gerenciamento pelas Diretrizes. São eles:

- habilidade em priorizar;

- plano baseado na voz do cliente;

- liderança da alta administração;

- desdobramento coeso do plano através da estrutura da empresa;

- amadurecimento do processo; e

- instrumentalização desburocratizada.

A Figura 3 apresenta a visão geral da nossa proposta. 


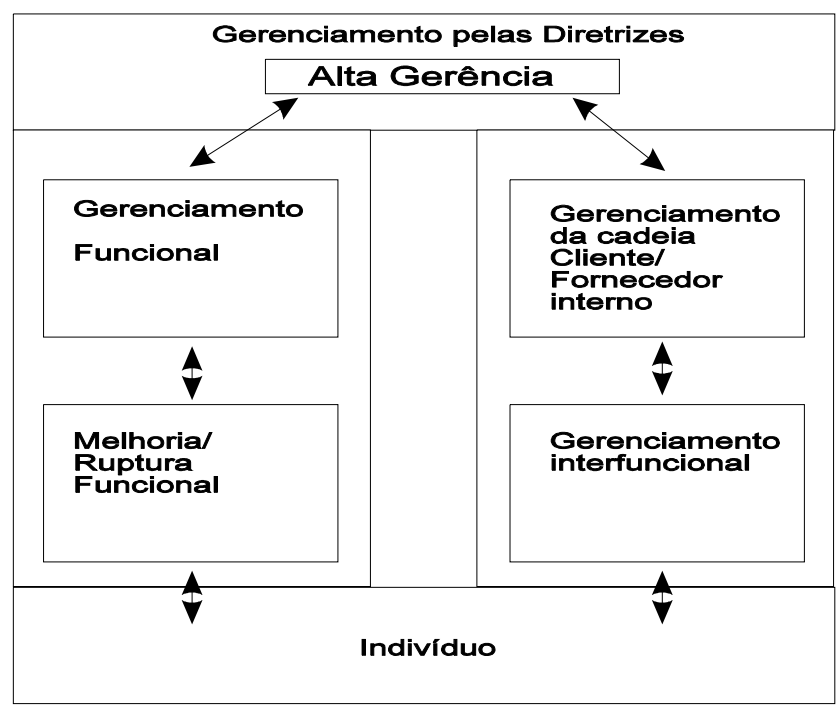

Figura 2 - Hierarquização do Gerenciamento pelas Diretrizes (MELUM \& COLLETT, 1995).

\section{O Processo de Estabelecimento das Diretrizes}

$\mathrm{E}$ xistem quatro etapas fundamentais que caracterizam o processo de estabelecimento das diretrizes:

- Etapa 1: escolha do foco;

- Etapa 2: alinhamento da organização;

- Etapa 3: implementação;

- Etapa 4: revisão/melhoria.

Por onde a empresa irá começar depende muito da existência ou não de atividades que já sejam exercidas com o objetivo de definir os objetivos de médio e longo prazo. Empresas que já possuem algum processo que leva em consideração as variáveis externas de mercado (ameaças e oportunidades) e as variáveis internas (pontos fortes e pontos fracos) podem, por vezes, começar sua implementação já na Etapa 2, alinhamento da organização. Para isto, entende-se que a empresa tem a seu dispor uma forma de priorizar as suas necessidades, e com isto consegue focalizar-se.

A Etapa 2, alinhamento da organização, constitui-se num trabalho que fundamentalmente depende da participação de todos os "supostos" envolvidos. Estes contribuem para o desdobramento dos objetivos anuais e para o estabelecimento dos meios que serão utilizados para alcançá-los. São utilizados mecanismos conciliadores, que promovem o estreitamento entre os objetivos previamente estabelecidos pela alta gerência e os níveis operacionais envolvidos.

Para sustentar a negociação existente nesta etapa, são utilizados os dispositivos estruturais, que se caracterizam por meio de uma diagramação apropriada a ser considerada cuidadosamente.

Uma vez que as partes tenham acertados os objetivos e os meios, a Etapa 3 é promover a implementação do plano de diretrizes, bem como seu monitoramento. Cada objetivo, com o seu meio associado, é rastreado qualitativa e quantitativamente, e os projetos são colocados em curso a partir do momento em que os recursos são postos à disposição.

Por fim, na Etapa 4, revisão/melhoria, é feita uma avaliação geral do progresso dos projetos, do processo gerador do resultado e do próprio resultado em si. Para isto, as seguintes atividades devem ser contempladas:

- diagnóstico e correção de problemas;

- disseminação do aprendizado para a organização;

- monitoramento dos resultados, considerando o planejado e o processo de execução do plano; e 


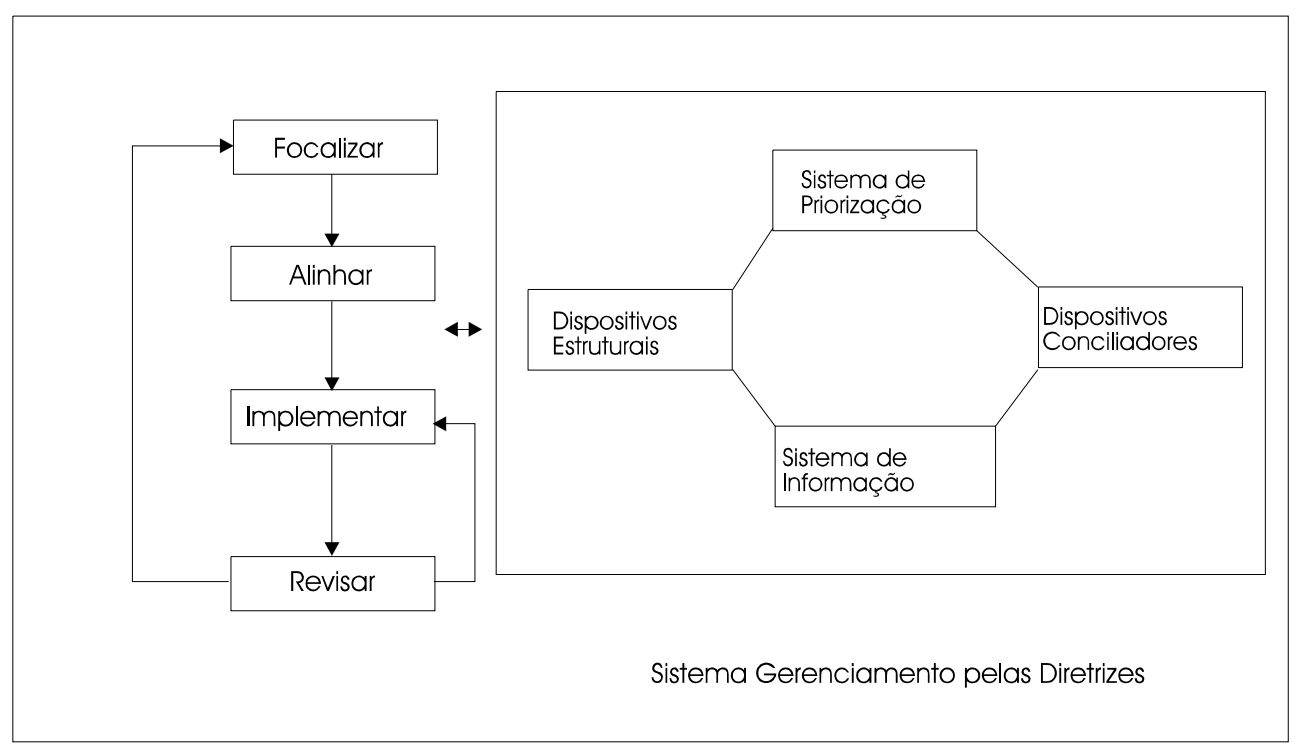

Figura 3 - Visão sistêmica do Gerenciamento pelas Diretrizes.

- reconhecimento e celebração do progresso conquistado.

As atividades que definem as diretrizes estão inseridas em dois ciclos de utilização do PDCA (Plan, Do, Check, Act): um ocorre anualmente e determina as novas diretrizes a serem implementadas a cada ano, e o outro ocorre mensalmente, quando se avalia o progresso em termos de se caminhar em direção ao que foi estabelecido.

Incluso nesta lógica tem-se a representação do passado, demonstrada nos planos anuais anteriores com os respectivos resultados; o futuro, representado pela visão, pelos planos de longo e médio prazo; e, por fim, o ambiente externo, que é caracterizado pelas mudanças que podem afetar a empresa, positiva ou negativamente.

Para a escolha do foco (Etapa 1) é interessante fazer a seleção das atividades a serem revistas, tendo-se em mente o nível de satisfação do cliente.

COLLINS \& HUGE (1993) propõem o tratamento da voz do cliente, explorando suas necessidades já pronunciadas, os seus desejos não revelados e, por fim, as suas reclamações oriundas de produtos ou serviços que apresentaram algum problema e acabaram deixando os clientes contrariados. Estes devem apontar para os processos críticos de negócio, tornando transparente a relação existente com os requisitos operacionais internos.

Muitos métodos podem ser encontrados para levantamento de desejos ainda não revelados. SHIBA et al (1993) propõem um método bastante simples, que constitui na ida a campo de um representante da empresa para colher, por meio de entrevistas informais, as manifestações expressas por clientes/usuários do produto/ serviço sobre características desejadas mas ausentes no produto. Este método é bastante parecido com o de outros autores, URBAN \& HIPPEL (1988), que propõem a ida de um representante da empresa a campo, e este, por meio de observação, tenta identificar necessidades ainda não atendidas pelo produto/serviço.

Para as necessidades pronunciadas a literatura vem caracterizando as pesquisas quantitativas, tipo questionário, previamente projetadas. Para elaboração deste tipo de captação de informação, as melhores referências são: NAUMANN \& GIEL (1995), HAYES (1991), LAKATOS (1990), MATTAR (1992a) e MATTAR (1992b), pois orientam desde o projeto da pesquisa até a sua análise, indicando uma série de cuidados a serem observados e levados em consideração, 
para evitar um comprometimento drástico dos resultados.

Para a coleta de informações que dizem respeito às reclamações, EDOSOMWAN (1993) estabelece um subsistema de monitoramento que não só organiza e registra as contrariedades dos clientes, mas também possibilita armazenar as ações que foram providenciadas para resolver as contrariedades manifestadas.

Para ter-se um quadro representativo da voz do cliente, basta consolidar todas as informações que podem ser obtidas pelas abordagens acima descritas, ou mesmo utilizar-se de informações conseguidas casuisticamente, por canais não padronizados de captação das informações. De posse desta consolidação, a empresa pode então escolher as prioridades a serem focalizadas.

Após a priorização das necessidades dos clientes ter sido definida, a tarefa seguinte é promover a sua tradução em Fatores Críticos de Sucesso (FCS). Estes estão associados diretamente com os processos ou atividades operacionais, e correlacionados com a voz do cliente.

Complementando o tratamento dado em termos do reconhecimento à voz do cliente, este primeiro passo do processo possui outros três estágios:

- análise da situação: levantamento das ameaças e oportunidades, além de avaliar todos os aspectos internos da empresa, que levaram-na eventualmente a um desempenho não desejado.

- planos finais: neste estágio, a empresa desenha inicialmente o que ela deveria ser hoje e, em seguida, deve idealizar o que gostaria de ser no futuro.

- estabelecimento dos meios: neste estágio, a empresa deve procurar estabelecer os meios dos quais irá lançar mão para alcançar o futuro delineado. Parte-se da situação futura idealizada e introduz-se nesta as restrições cabíveis, até chegar à situação atual. Segundo SHIBA et al (1993), esta é uma forma ideal e proveitosa de se determinar as ações necessárias para o estabelecimento de um plano anual, que colocará a empresa em busca daquilo que representa o seu futuro:

\author{
visão futuro \\ $\Downarrow$ \\ restrição A \\ $\Downarrow$ \\ situação menos idealizada \\ (considera a restrição A). \\ $\Downarrow$ \\ restrição B \\ $\Downarrow$ \\ $\Downarrow$ \\ situação atual
}

\subsection{O Subprocesso de Priorização}

Como visto anteriormente, é necessário o estabelecimento sistemático de um foco que caracterize as áreas que sofrerão intervenção mediante uma inovação. Para isto, pode ser utilizado um Sistema de Apoio à Decisão (SAD). Os SAD's são sistemas de informação, em geral, computadorizados, que têm como objetivo auxiliar o processo de tomada de decisão, conforme SPRAGUE \& WATSON (1991). Propicia para a alta gerência uma análise dos dados que são relevantes sob o ponto de vista das necessidades e do nível de satisfação dos clientes, caracterizando-se como um provedor das informações preliminares que serão levadas em consideração na priorização dos projetos.

A partir destas informações preliminares que caracterizam a voz do cliente, MELUM (1995) propõe uma atividade que, num primeiro instante, transforma os requisitos do cliente ou suas necessidades em Fatores Críticos de Sucesso (FCS's). Estes fatores são os elementos que caracterizam os requisitos operacionais internos, responsáveis pelo atendimento do que foi apontado pela voz do cliente. Em seguida, é feita uma análise de "gap", que é a diferença entre a pontuação preliminar dos requisitos (FCS) sem considerar a voz do cliente e a pontuação que cada FCS deveria apresentar hipoteticamente, isto é, segundo a ótica do cliente. Por fim, é feita uma análise de correlação entre os FCS's, para saber qual ou quais influencia(m) decididamente 
o(s) outro(s). E, então, destacam-se aqueles principais, que deverão ter seus provedores (processos ou atividades cotidianas) escolhidos para serem contemplados com um projeto de melhoria e/ou inovação (projetos da qualidade).

Os FCS's definidos têm um papel fundamental para a boa ou má condução do restante do processo, pois é por meio deles que a empresa estabelece, para os vários níveis operacionais, aquilo que deseja abordar e perseguir como forma de melhorar o seu posicionamento no mercado (nível de satisfação do cliente). Eles são utilizados para sustentar uma negociação feita internamente. Constituem-se no conteúdo a ser explorado por meio dos dispositivos estruturais e por meio dos dispositivos conciliadores.

\subsection{Os Dispositivos Estruturais}

Para descrever os dispositivos que servem de elementos básicos e que são utilizados no exercício de desdobramento das diretrizes, optou-se em fazer a seguinte distinção:

- mecanismo de desdobramento síncrono "top-down" e "bottom-up": serve para sustentar a coesão do desdobramento das diretrizes (objetivos/meios) entre os vários níveis da empresa.

- mecanismo de monitoramento: serve para manter as informações atualizadas a todo momento, refletindo o estado presente daquela atividade e/ou processo que tenha sido escolhido para promover a inovação.

Inicialmente, fazendo parte do primeiro grupo, é disponibilizada a diagramação conforme apresentada na Figura 4. Esta orienta o desdobramento do objetivo ou alvo/meio, considerando os vários níveis da empresa. Nela pode ser vista a transformação do meio no nível 1, em objetivo no nível 2. Isto ocorre até se chegar no nível operacional, onde as ações ocorrem efetivamente.

Esta estrutura é suficientemente simples e sustenta as discussões existentes quando o plano anual está sendo concebido, permitindo caracterizar uma padronização na comunicação sobre os pontos em questão.
A matriz X, conforme descrita em MIZUNO (1992), pode ser utilizada para estabelecer uma visão geral da consolidação dos resultados obtidos com o exercício de desdobramento das diretrizes. As informações nela organizadas permitem avaliar a consistência geral do desdobramento realizado e identificar alguma distorção não percebida anteriormente. Podemos ter uma visão sistêmica com as respectivas traduções do que foi estabelecido no primeiro nível para os outros níveis da empresa.

Para manter a integração entre as partes do sistema, utilizam-se mecanismos como o "flag method" já na fase de implementação das diretrizes, sugerido em AKAO (1991). Este mecanismo possibilita aos responsáveis e colaboradores monitorarem a evolução daquilo que foi projetado. É uma avaliação, em "tempo real”, da evolução global do plano traçado. Sua implementação dá-se por meio da concepção de um sistema de gestão à vista e deve refletir os objetivos estabelecidos, que são avaliados pelos chamados pontos de controle, os quais determinam decididamente o desempenho dos FCS's.

Desta forma, os mecanismos de sustentação do Gerenciamento pelas Diretrizes procuram proporcionar uma praticidade em termos de atualização e utilização das informações, viabilizando aos envolvidos uma transparência objetiva entre os níveis hierárquicos da empresa, promovendo forte interação entre estes.

\subsection{Os Dispositivos Conciliadores}

Os dispositivos conciliadores foram assim definidos por se tratarem de uma abordagem face a face, que deve ser estabelecida envolvendo o indivíduo ou grupos de indivíduos, com o objetivo de transformarem os objetivos/meios gerais da empresa em objetivos/meios das pessoas em termos de trabalho a ser realizado.

Neste contexto, são reconhecidos dois dispositivos conciliadores:

- o "catchball": por meio de uma interação, em que a comunicação e a negociação são os principais ingredientes, os objetivos e meios 


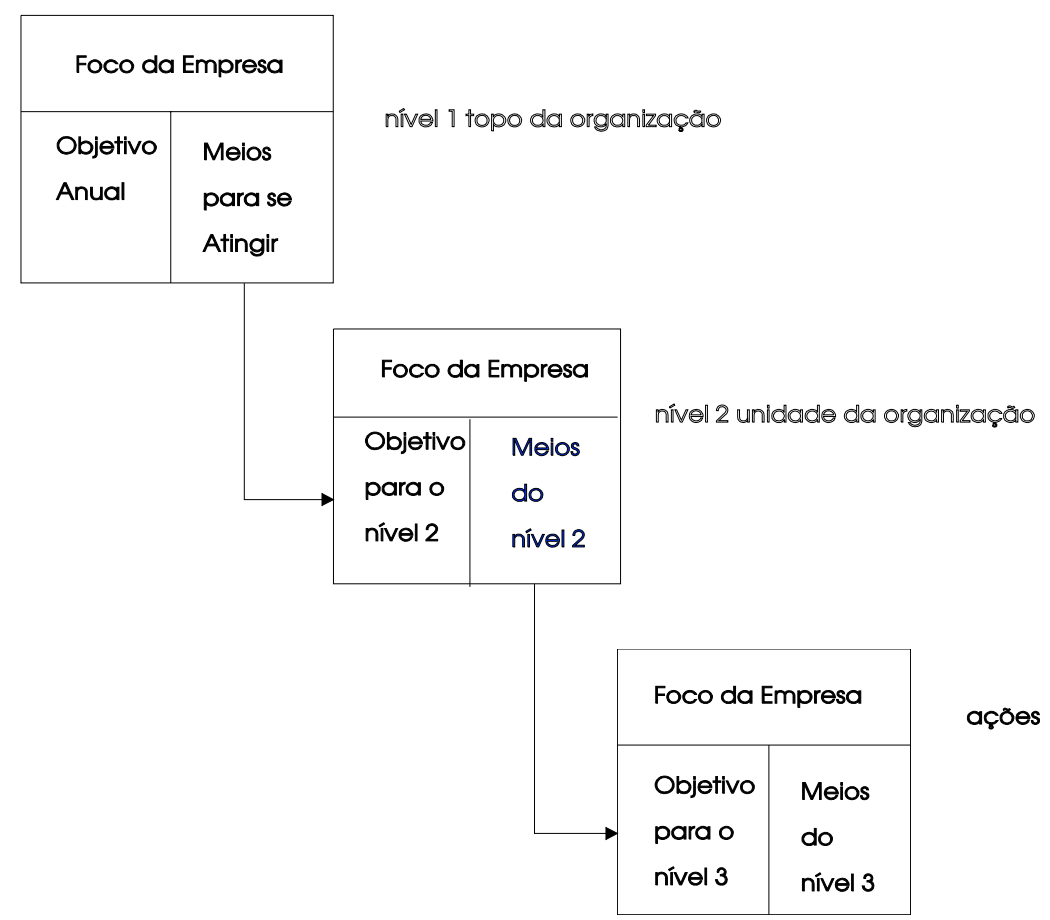

Figura 4 - Desdobramento Objetivo/Meios (AKAO, 1991).

delineados pela alta administração são convertidos seqüencialmente em termos de objetivos/meios da unidade, do departamento, do grupo de trabalho, até se chegar na pessoa. Começa com o primeiro nível gerencial lançando a "bola" - a tarefa a ser acompanhada - para o nível imediatamente inferior, fazendo a seguinte pergunta: "Quais são as atividades que você pode fazer (meios) para me ajudar a atingir esta tarefa, a qual de agora em diante é seu objetivo?" Este processo continua até se atingir todos os níveis da empresa que estariam envolvidos, "a priori", com a questão escolhida. Quando isto acontece, faz-se o exercício no sentido contrário, ou seja, "bottom-up". Cada grupo lança a bola no sentido oposto, percorrendo nível por nível, e perguntando para o nível superior: "Meus meios contribuem suficientemente e adequadamente para se atingir o objetivo definido pela organização?", "Ele é realizável?", "Como nossos meios propostos contribuem com os outros na empresa?" Desta maneira, o foco estabelecido inicialmente torna-se mais palpável para todos os envolvidos, pois é traduzido em ações de que devem ser realizadas pelos participantes do processo.

- o diagnóstico: esta atividade deve ser, preferencialmente, realizada pelo presidente da empresa. Todo ano, o presidente avalia como cada divisão ou departamento conduziu suas atividades associadas ao planejamento pelas diretrizes, desenvolvendo os quatro passos seguintes:

$\Rightarrow$ o primeiro passo: o grupo a ser auditado deve prover um relatório que mostra o "status" da situação. O presidente, acompanhado por um agente externo e o time de diagnóstico, visita o ambiente de trabalho do grupo;

$\Rightarrow$ o segundo passo consiste em duas partes: a primeira é formal, o grupo faz a apresentação do trabalho de campo; a segunda é pessoal e informal, o presidente visita novamente o ambiente onde se encontra o grupo;

$\Rightarrow$ o terceiro passo: começa quando o presidente, ainda em visita, é alertado pelo a- 
gente externo dos pontos fracos e dos pontos fortes que foram captados; é quando o presidente, usando de suas atribuições, promove uma manifestação no sentido de ter fortalecido e estimulado os indivíduos a continuarem em busca daquilo que foi estabelecido;

$\Rightarrow$ o quarto passo: o presidente, juntamente com seu corpo diretivo, planeja como melhorar o processo de diagnóstico para o próximo ano.

Esta atividade atende a muitos propósitos; o principal é:

- a definição do sistema "nervoso" do planejamento pelas diretrizes, indo de encontro a um conceito encontrado no "just in time", como descrevem OHNO \& MITO (1988). Para isto, as datas das visitas são planejadas com um ano de antecedência, o que acaba impondo um planejamento minucioso no sentido de ser obtido o melhoramento da qualidade dentro do prazo previsto;

Outros dois propósitos merecem também destaque:

- a própria atividade de diagnóstico que orienta como melhorar o sistema da qualidade, tornando-o mais coeso com a missão da empresa. Lembre-se que o diagnóstico não é para verificar resultados, mas sim para avaliar e melhorar os provedores, atividades e processos;

- o diagnóstico possibilita ao próprio presidente um processo de auto-aprendizado e serve ainda para ele demonstrar sua liderança no programa da qualidade em curso.

Como visto, os dispositivos conciliadores são estabelecidos para proporcionar a participação efetiva da alta administração nos níveis operacionais. Por isto, eles acabam criando um desafio em termos gerenciais, que deve ser tratado criteriosamente, sob pena de ter todo o processo de Gerenciamento pelas Diretrizes destruído, pois aqui talvez resida um aspecto delicado em termos de assumir o compromisso com o que foi definido previamente.

\subsection{O Sistema de Informação}

O sistema de informação é definido aqui como sendo um composto dos Sistemas de Gestão à Vista (SGAV), proposto em GREIF (1993), com as informações dos processos e as informações formais e informais que representam a voz do cliente, caracterizando um subsistema de informação orientado ao suporte do Gerenciamento pelas Diretrizes.

Os Sistemas de Gestão à Vista são exemplificados por, praticamente, qualquer estrutura visual de comunicação utilizada, seja na fábrica, seja no escritório, atendendo a objetivos, geralmente, específicos.

Para melhor compreensão do sistema de informação, dois aspectos devem ser considerados:

- a arquitetura do Sistema de Gestão à Vista e sua base de dados correlata, que serve para caracterizar a memória do sistema como um todo;

- os dados que são efetivamente apontados no sistema de gestão e também aqueles que servem de suporte para decisão.

Olhando para a arquitetura do Sistema de Gestão à Vista, deve-se, inicialmente, levar em consideração que este não só dá suporte ao sistema de decisão da empresa, como acima de tudo é um sistema de comunicação. Para os primeiros projetos sua configuração deve considerar o tempo a ser gasto para sua elaboração, local de exposição, o que se pretende informar e a quem, devendo ser a sua utilização o mais amigável possível, tanto do ponto de vista de quem lhe dá manutenção quanto de quem utiliza as informações contidas nele. A empresa deve buscar, por meio de um aprendizado constante, uma padronização em termos de sua arquitetura, mudando inclusive as rotinas burocráticas que por vezes a afetam.

No segundo grupo estão as informações propriamente ditas, que são lançadas periodicamente no sistema de gestão. Estas, por vezes, podem vir a requerer uma ou mais operações que são consolidadas num indicador existente no sistema. Esta característica pode, como no caso 
anterior, exigir uma reconfiguração do sistema que compila e consolida a informação a ser lançada.

Para as informações que são utilizadas na primeira etapa do processo característico, deve ser considerada a possibilidade delas existirem de forma esparsa, isto é, distribuídas nos vários sistemas de informação existentes na empresa. Neste caso, deve ser feito um esforço ao longo dos anos no sentido de adequar e facilitar a obtenção das informações, possibilitando um pronto atendimento à demanda requerida no estabelecimento das diretrizes anuais.

\section{As Implicações Práticas}

$\mathrm{O}$ modelo teórico proposto foi aplicado no desenvolvimento e implementação de diretrizes numa empresa de distribuição de cerveja. A idéia foi, por meio da pesquisa-ação, como propõe THIOLLENT (1997), estabelecer um processo de intervenção, a fim de avaliar o modelo submetendo-o a um teste controlado.

A estrutura organizacional da empresa em questão possui uma diretoria com três departamentos distintos: Administração e Finanças, Logística e Vendas. Estão subordinados ao Departamento de Administração e Finanças as áreas de Pessoal, Informática, Faturamento e Contas a Receber. O Departamento de Logística conta com uma supervisão de tráfego, que é responsável pela planejamento e controle dos roteiros de viagens. O Departamento de Vendas possui três supervisores, com uma equipe de vendas de seis colaboradores cada um, e um supervisor de telemarketing. No total a empresa possui cento e quinze funcionários e $60 \%$ estão alocados no Departamento de Logística.

A Distribuidora é orientada, controlada e avaliada por um Programa de Exelência em Revendas concebido e editado pelo fabricante. A empresa restringe-se a cumprir exigências estabelecidas neste instrumento de avaliação e não utiliza outros meios para aprimoramento do nível de prestação de serviço oferecido ao mercado.
A empresa não possui um processo de planejamento formalizado. Suas decisões, na maioria das vezes, são articuladas e efetivadas em conversas informais.

A intervenção realizada foi acertada com os diretores da empresa, que estavam interessados em eliminar alguns problemas crônicos existentes. Pelo nosso lado, optamos em não explicitar o modelo de referência que estaria sustentando a intervenção, não vimos utilidade para isto. Em termos operacionais, adotou-se uma estratégia alternativa daquela comumente utilizada neste tipo de intervenção, em que o prestador de serviço orienta a implementação, desempenhando um papel consultivo. Neste caso o prestador de serviços desempenhou um papel ativo no processo, realizando trabalhos efetivos a nível operacional.

Inicialmente foi estabelecido o objetivo que seria a melhoria do nível de serviço oferecido ao cliente, conforme Figura 5.

Avaliada as condições operacionais, concluiu-se que seria possível abordar de uma só vez todos os objetivos desdobrados de segundo nível. Portanto, os esforços foram concentrados no primeiro, que seria eliminar a falta de produtos para a entrega. Esta decisão foi tomada pela diretoria, foi entendido que se o controle de estoque fosse implementado a empresa passaria a ter uma visibilidade do fluxo de produtos, permitindo a viabilização de técnicas de previsão, uma vez que as informações referentes aos produtos em estoque seriam verdadeiras.

Para tratar este problema operacional, foi constituída uma equipe "informal", composta de representantes das seguintes áreas: informática, logística (movimentação de produtos) e faturamento.

$\mathrm{Na}$ atividade de implementação do projeto foram usadas ferramentas e metodologias típicas da gestão pela qualidade total: análise e solução de problemas, melhoria da rotina.

Como aprendizado deste processo de intervenção destacamos os seguintes pontos:

- o sistema de priorização: de fato, apesar de informal, há um processo de priorização. 


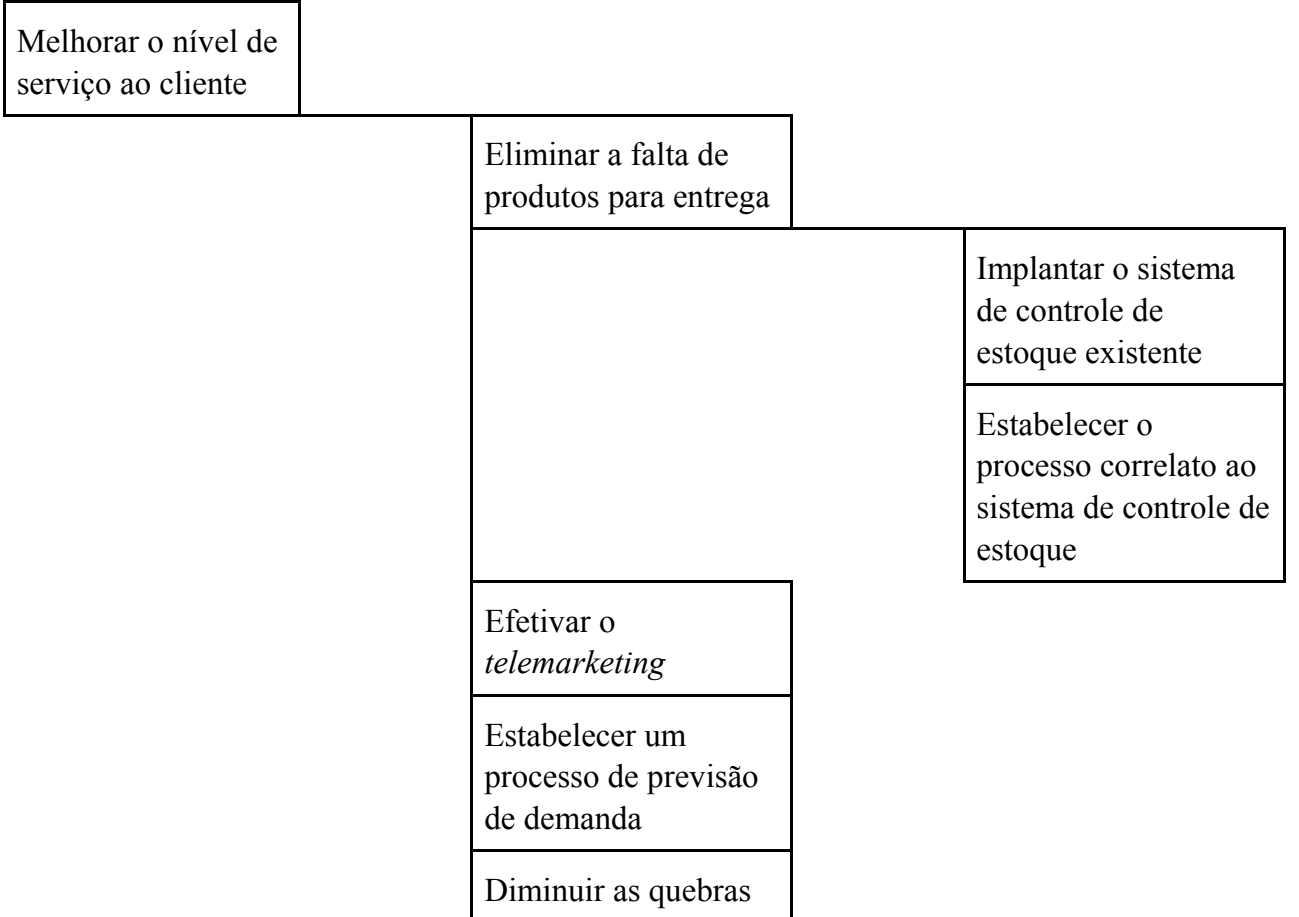

Figura 5 - Desdobramento dos objetivos.

Neste processo o foco é o nível de serviço ao cliente, mas com o passar do tempo ficou claro que o objetivo efetivo seria a diminuição ou eliminação por completo de fraudes existentes e de fato constatadas. Em termos do modelo proposto não houve modificação a ser acrescentada, exceto pelo fato da descaracterização do objetivo explícito declarado.

- os dispositivos estruturais: foram utilizados conforme descritos. O desdobramento dos objetivos foi realizado, havendo uma explícita alocação de recursos para o projeto.

- os dispositivos conciliadores: o "catch-ball" foi utilizado naturalmente, entretanto, foi necessário estabelecer um monitoramento efetivo da operacionalização, ou seja, em alguns casos, após a apresentação de uma idéia, não ocorreu o "feedback" por parte do colaborador, fazendo com que houvesse uma cobrança formal. Este comportamento se dava por várias razões: desmotivação, sentimento de desrespeito da empresa para com o funcionário, desenvolvido ao longo da rela- ção trabalhista, caracterizando muitas vezes um estado de resignação e envolvimento em fraudes contra a empresa.

- o diagnóstico: este teve que ser modificado substancialmente quando comparado à proposta inicial do modelo. No modelo pressupõe-se que os gerentes de área ou departamento irão se envolver e se responsabilizar pela implementação de projetos que sustentam o GD. Nos momentos iniciais, tentou-se esta estratégia mas foi inócuo, as ações não se realizaram. Além disto, os dirigentes principais estavam mais preocupados com os resultados do que com o processo em si.

Assim estabeleceu-se a figura do AGENTEINTERVENTOR (AI) que foi responsável pelo encaminhamento das atividades. O AI teve acesso a todos os níveis, e atuava como facilitador.

$\mathrm{O} \mathrm{AI}$ ao mesmo tempo que intervinha nas áreas correlacionadas com o problema, reportava à gerência superior os fatos ocorridos, destacando as principais dificuldades encontradas. Por causa dos diferentes perfis profissionais e grau 
de instrução da equipe, assumiu estilos diferenciados de LIDERANÇA.

No primeiro caso, pessoal com nível superior e com conhecimento das atividades, trabalhou-se com o estilo tipo VENDA e às vezes DELEGAÇÃ̃o, enquanto no segundo, pessoal sem qualquer formação e com pouco conhecimento das atividades, trabalhou-se com o estilo, predominante, COMANDO, e às vezes VENDA conforme HERSEY \& BLANCHARD (1972).

$\mathrm{O}$ AI teve que adquirir conhecimentos técnicos profundos e multivariados das atividades internas para efetivar o processo de mudança na empresa. Começou pela implantação do controle de estoque, para isto fez prevalecer a autoridade (liderança) técnica, conforme MAXIMIANO (1995), com o intuito de desarticular justificativas que prejudicavam o avanço do processo.

O tempo estimado para realização deste projeto foi de 8 meses, mas foram gastos 12 meses. O atraso ocorreu, principalmente, pelos boicotes implícitos praticados pelos empregados. Motivo que enriqueceu suficientemente o trabalho de pesquisa-ação em questão, e comprovou a necessidade de empregar os estilos de liderança descritos.

\section{Conclusão}

$\mathrm{O}$ artigo propôs estabelecer um modelo sistêmico do Gerenciamento pelas Diretrizes. Este modelo representa uma articulação de vários elementos que compõem propostas de outros autores. O propósito foi estabelecer um modelo orgânico menos instrumental e mais conceitual, de tal modo que pudesse ser aplicado e aprimorado às empresas de médio e pequeno porte que não possuem estruturas otimizadas.

Por meio da pesquisa-ação planejou-se uma intervenção, que corroborou parte dos elementos do modelo. Os dispositivos conciliadores foram reformulados. Nesta reformulação foi introduzido explicitamente o agente-interventor, que na função de assessoria exerceu diferentes estilos de liderança.

Muitas críticas podem ser elaboradas contra esta abordagem enquanto solução adotada. Entretanto, pensa-se que a configuração do AI agrega um elemento importante no Gerenciamento pelas Diretrizes, quando explicita a necessidade de ser desenvolvida a liderança situacional conforme descrita.

\section{Referências Bibliográficas}

AKAO, Y.: Hoshin Kanri. Productivity Press, Cambridge, 1991.

CAMPOS, V.F.: Qualidade Total. Fundação Christiano Ottoni, Belo Horizonte, 1992.

COLLINS, B. \& HUGE, E.: Management by Policy. ASQC Press, Milwaukee, 1993.

DAVENPORT, T.H.: Reengenharia de Processos. Campus, São Paulo, 1993.

EDOSOMWAN, J.A.: Customer and Market-Driven Quality Management. Quality Press, Milwaukee, 1993.

GALGANO, A.: Companywide Quality Management. Productivity Press, Cambridge, 1994.

GREIF, M.: The Visual Factory. Building Participation Through Shared Information. Productivity Press, Portland, 1993.
HARRIGNTON, H.J.: O Processo do Aperfeiçoamento. Como as empresas americanas líderes de mercado aperfeiçoam o controle de qualidade. McGraw-Hill, São Paulo, 1988.

HARRIGNTON, H.J.: Aperfeiçoando Processos Empresariais. McGraw-Hill, São Paulo, 1993.

HAYES, B.E.: Measuring Customer satisfaction. Development and Use of Questionnaries. ASQC Quality Press, Milwaukee, 1991.

HERSEY, P. \& BLANCHARD, K.: Management of organizational behavior. Englewood Cliffs, New Jersey: Prentice-Hall, 1972.

LAKATOS, E.: Técnicas de Pesquisa. Atlas, São Paulo, 1990.

MATTAR, F.N.: Pesquisa de Marketing 1. Atlas, São Paulo, 1992. 
: Pesquisa de Marketing 2. Atlas, São Paulo, 1992.

MAXIMIANO, A.C.A.: Introdução à Administração. Atlas, São Paulo, 1995.

MELAN, E.H.: Process Management. Methods for Improving Products and Services. McGraw-Hill, New York, 1992.

MELUM, M.M. \& COLLETT, C.: Breakthrough Leadership. Goal QPC Press, Methuen, 1995.

MERLI, G.: Eurochallenge. The TQM Approach to Capturing Global Markets. IFS, Londres, 1993.

MIZUNO, S.: Gerência para a Melhoria da Qualidade. LTC, Rio de Janeiro, 1992.

: Company-Wide Total Quality Control. Asian Productivity, Tóquio, 1989.

MORAN, J.W; COLLETT, C. \& CÔTÉ, C.: Daily Management. A System for Individual and Organizational Optimization. Goal QPC Press, Methuen, 1991.
NAUMANN, E. \& GIEL, K.: Customer Satisfaction. Measurement and Management. Thomson Executive Press, New York, 1995.

OHNO, T. \& MITO, S.: Just-in-Time. Today and Tomorrow. Productivity Press, Cambridge, 1988.

SHIBA, S.; GRAHAM, A. \& WALDEN, D.: A new american TQM. Four Practical Revolutions in Management. Productivity Press, Cambridge, 1993.

SPRAGUE, R.H. \& WATSON, H.J.: Sistema de Apoio à Decisão. Colocando a Teoria na Prática. Campus, São Paulo, 1991.

THIOLLENT, M.: Pesquisa-ação nas Organizações. Atlas, São Paulo, 1997.

URBAN, G.L. \& HIPPEL, E.V.: "Lead user analyses for the development of new industrial products". Management Science, v. 34, n. 5, p. 569-582. May 1988.

\section{A SYSTEMATIC APPROACH TO POLICY DEPLOYMENT: CONCEPT AND APPLICATION}

\section{Abstract}

This article presents the theoretical model of policy deployment, exploring and organizing its organic features. At first, the featuring process is established, afterwards four complementary elements are defined: the priority system, the structural devices, the conciliatory devices and the information system.

The test is done by research method, "research by intervention in one reality". The intervention was promoted in a beer retailer that operates covering a wide geographic area. New findings were gotten therefore leading condition to improve the model proposed.

Key words: total quality management, policy deployment. 